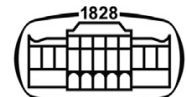

AKADÉMIAI KIADÓ

Developments in Health Sciences

2 (2019) 4, 108-113

DOl:

10.1556/2066.2019.00006

(c) 2019 The Author(s)

\section{ORIGINAL ARTICLE}

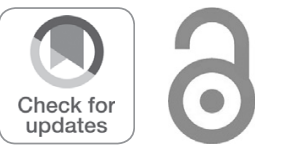

\title{
Postpartum female sexual dysfunctions in Hungary: A cross-sectional study
}

\author{
Oral presentation at the 13th Conference of the Hungarian \\ Medical Association of America - Hungary Chapter (HMAA-HC) \\ at 30-31 August 2019, in Balatonfüred, Hungary
}

\author{
K. SZÖLLŐSI ${ }^{1,2 *}$ and L. SZABÓ ${ }^{1,3}$ \\ ${ }^{1}$ Department of Family Care Methodology, Faculty of Health Sciences, Semmelweis University, \\ Budapest, Hungary \\ ${ }^{2}$ Doctoral School of Pathological Sciences, Semmelweis University, Budapest, Hungary \\ ${ }^{3}$ Heim Pál National Pediatric Institute, Budapest, Hungary
}

Received: November 27, 2019 • Revised manuscript received: February 26, 2020 • Accepted: March 9, 2020 Published online: July 31, 2020

\begin{abstract}
Purpose: Although the prevalence of sexual dysfunction after delivery is generally considered high, this has not been well examined in Hungary. The aim of our study was to evaluate female sexual function at 3-months postpartum and to investigate some of the possible predictor factors which might influence it. Materials and Methods: We designed a cross-sectional study using online questionnaires and recruited 253 participants. Risk factors such as infant-feeding method and urinary incontinence were assessed for a potential relationship with sexual dysfunction. The Female Sexual Function Index (FSFI) was used to assess sexual function. We wrote our own questions about potential predictors. Results: $48.79 \%$ of participants reported sexual dysfunction according to total FSFI score $(M=25.16, \mathrm{SD}=7.00)$. A significant relationship was found between infant-feeding method and sexual dysfunction $(P=0.003)$. Sexual dysfunction was more common in exclusive-breastfeeding mothers than in mixed or formulafeeding mothers. Women with urinary incontinence had significantly lower total FSFI scores $(P=$ $0.006)$, and in the arousal $(P=0.033)$, lubrication $(P=0.022)$, satisfaction $(P=0.006)$ and pain $(P=$ 0.032) domains compared to women with no incontinence problem. Conclusions: Women suffering from urinary incontinence are more likely to have sexual problems, especially a higher risk of dyspareunia and a lower level of sexual interest and wetness. Exclusive breastfeeding has a negative effect on sexual function.
\end{abstract}

\section{KEYWORDS}

sexual dysfunction, female sexual function index, breastfeeding, urinary incontinence

\section{INTRODUCTION}

*Corresponding author. Department of Family Care Methodology, Faculty of Health Sciences, Semmelweis University, Vas utca 17, Budapest, $\mathrm{H}-1088$, Hungary.

E-mail: szollosi.katalin@se-etk.hu
Sexual dysfunction is a heterogeneous group of disorders which affect the capacity for sexual response or sexual pleasure. These disorders have been related to biological, psychological, cultural, behavioural, and interpersonal determinants. Sexuality is an important part of a woman's health and is profoundly affected by her state of pregnancy. Most of the studies on this subject indicate an impairment of sexual function during the first 6 months after delivery [1-3].

Female sexual dysfunction includes disorders such as the experience of pain or the lack of desire, arousal, lubrication, orgasm, or satisfaction. According to the Diagnostic and 
Statistical Manual of Mental Disorders classification (5th edition), female sexual disorders (FSD) include sexual interest or arousal disorder, orgasmic disorder, and genitopelvic pain or penetration disorder. For these to be diagnosed, the symptoms must be present for at least 6 months and occur with a frequency of $75-100 \%$. The disorder also must cause significant distress [4].

It is difficult to measure the prevalence of sexual dysfunction and make comparisons of mothers after birth. Pre-pregnancy level of sexual function, relationship problems, mode of delivery, infant feeding method, and time of examination all have to be considered. The majority of women resume sexual activity at 6-10 weeks after delivery, and $30-70 \%$ of them report difficulties in sexual function at about 3 months postpartum [5-7]. Among 22-40\% of women, sexual function is still not recovered completely by 6 months postpartum $[8,9]$.

\section{Infant feeding method}

The World Health Organization defines exclusive breastfeeding as no other food or drink, not even water, except breast milk (including milk expressed or from a wet nurse) but allows the infant to receive oral rehydration solution (ORS), drops, and syrups (vitamins, minerals and medicines). Exclusive breastfeeding is recommended in the first 6 months after delivery due to several short and long-term benefits for babies and mothers [10].

International studies of the relationship of the infantfeeding method with sexual dysfunction are deficient or controversial. Chayachind found no relationship between infant-feeding method and sexual dysfunction [11]. According to Anbaran's study, breastfeeding mothers report the highest level of sexual function [12]. Escasa also found that breastfeeding mothers report the highest level of sexual function after birth [13]. In contrast to these results, other studies show that breastfeeding women are more likely to have sexual dysfunction. According to the latest results, sexual dysfunction and especially dyspareunia is associated with breastfeeding within the first 6 months postpartum [2, 14-17].

\section{Urinary incontinence}

Urinary incontinence (UI) is defined by the International Continence Society as the complaint of any involuntary leakage of urine [18]. Around $30-40 \%$ of women have urinary incontinence within 6 months after delivery [19]. In Brown's study, $47 \%$ of women still suffered from urinary incontinence 12 months after delivery [20]. The relationship between pelvic-floor muscle strength and sexual dysfunction has been investigated several times, but the results are unclear. According to Su's study, urinary incontinence is related to sexual dysfunction and can be considered a risk factor for decreased lubrication and increased pain [19]. Ozkan also found that incontinence has a negative effect on overall sexual function, but especially in the pain domain [21]. In addition, women reporting low sexual desire commonly suffered from stress incontinence (47\%)
[22]. In contrast to these studies, Baytur found no relationship between pelvic-floor muscle strength and sexual dysfunction [23].

Despite the increasing number of international studies, no studies have been conducted with Hungarian women to evaluate sexual function after delivery. The aim of our study was to assess sexual dysfunction among Hungarian women after delivery and to examine the time of sexual resumption in the postpartum period. We also investigated potential risk factors of postpartum female sexual dysfunction such as urinary incontinence and infant-feeding method.

\section{MATERIALS AND METHODS}

This study was carried out in three obstetric clinics in Budapest, Hungary. A total of 253 females were involved. The invitation period was between June 2018 and June 2019. Inclusion criteria included women with singleton pregnancies, age 18-45 years, in a relationship with their partner currently and for at least 6 months before the pregnancy. Exclusion criteria were high-risk pregnancy, delivery with complications, and delivery before the 37 th gestation week. Participants applied voluntarily and agreed to take part in the study by signing statements of consent.

This was a cross-sectional study 3 months postpartum using an online questionnaire posted by Survey Monkey, a General Data Protection Regulation compliant survey program that facilitates market and scientific research surveys. Women were evaluated at 3 months postpartum using a structured questionnaire to assess socio-demographic determinants such as age, educational level, partner's educational level, family income, employment, place of living, and parity.

Urinary incontinence was assessed by our own questions, for example, Have you experienced urine leakage since your last delivery? The frequency of leakage was detected with a Likert-type of scale (never; rarely; sometimes; every day, many times a day; constantly). The onset of incontinence was determined to understand its profile (before delivery, after delivery), but we did not differentiate between groups during the analysis.

To distinguish the infant feeding method, women were asked to describe how their babies were fed. The potential answers were exclusive breastfeeding (the woman feeds her baby only with breastmilk, the baby does not have any other liquid, solid, or formula except minerals, vitamins, or medicines), mixed feeding (the baby is fed with both breastmilk and formula) and formula feeding (the baby is fed only with formula). Those who indicated breastfeeding were asked whether they were breastfeeding on demand and whether they suffered from bleeding or painful nipples in the last four weeks.

Sexual life was assessed by the Hungarian version of the Female Sexual Function Index (FSFI). The FSFI is a validated and reliable measure of female sexual function. It consists of 19 questions that assess the six domains of sexual function: desire, arousal, lubrication, orgasm, satisfaction, 
and pain. The total score scale ranges from 2 to 36 , and the FSFI total score indicates the general status of sexual function [24]. The scale's cut-off value is 26.55. A total FSFI score of 26.55 or less indicates sexual dysfunction, while greater than 26.55 indicates normal sexual function [25].

Descriptive statistics were used to present the socio-demographic data and independent variables using mean, standard deviation, range, frequency, and percentage. Nonparametric tests were used to assess the association between infant feeding method and FSFI scores, as well as between urinary incontinence and FSFI scores.

The research was permitted by Semmelweis University's Regional Research Ethics Committee (SE REB number: 24/ 2017).

\section{RESULTS}

The mean age of the women was 32.39 ( $\mathrm{SD}=4.61)$. The mean of years in the relationship was 7.38 years $(\mathrm{SD}=4.56)$. A majority $(70.8 \%)$ of the women were college-educated. $75.1 \%$ were married, $24.9 \%$ were in a relationship. $83.3 \%$ assessed their income as 4 or 5 in a 5 item Likert scale. $60.19 \%$ of the women were primiparous.

$81.81 \%$ of the women resumed their sex life at 3 months postpartum. The mean of the time of sexual resumption was 2 months after delivery (Fig. 1). A majority of the women (87.9\%) waited until 6 weeks postpartum for first sexual intercourse.

The mean of total FSFI scores was $25.16(\mathrm{SD}=7.00)$ among women who had already resumed their sex life (Fig. 2). According to the FSFI scores, the prevalence of postpartum sexual problems was $48.8 \%$.

$28.1 \%$ of the women reported urinary incontinence problems. $27.1 \%$ of the women who had resumed their sex life suffered from urine leakage. Based on the results of the Mann-Whitney U Test, women with urinary incontinence had significantly lower FSFI scores $(P=0.006)$ (Fig. 3 ).

We also found significantly lower scores in the arousal, lubrication, satisfaction, and pain domains. Incontinence

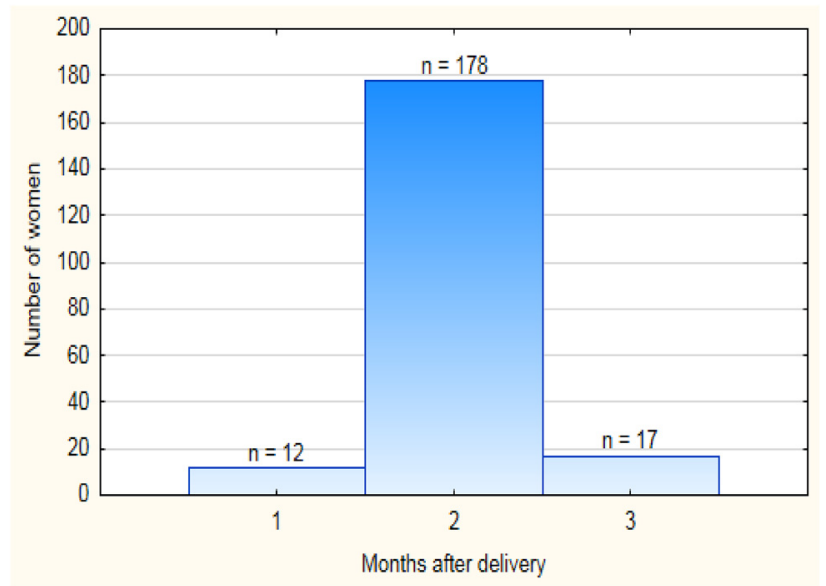

Fig. 1. Time of sexual resumption after delivery $(n=207)$

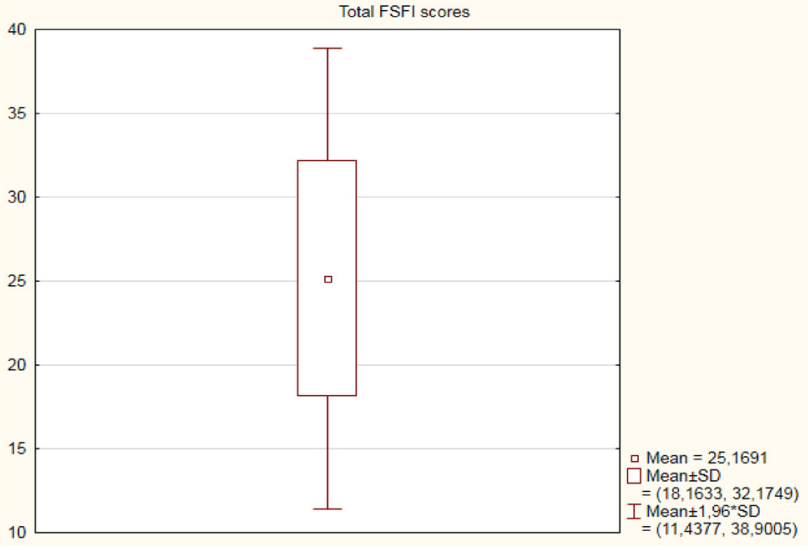

Fig. 2. Mean of total FSFI scores among women who restarted their sexual life after delivery $(n=207)$

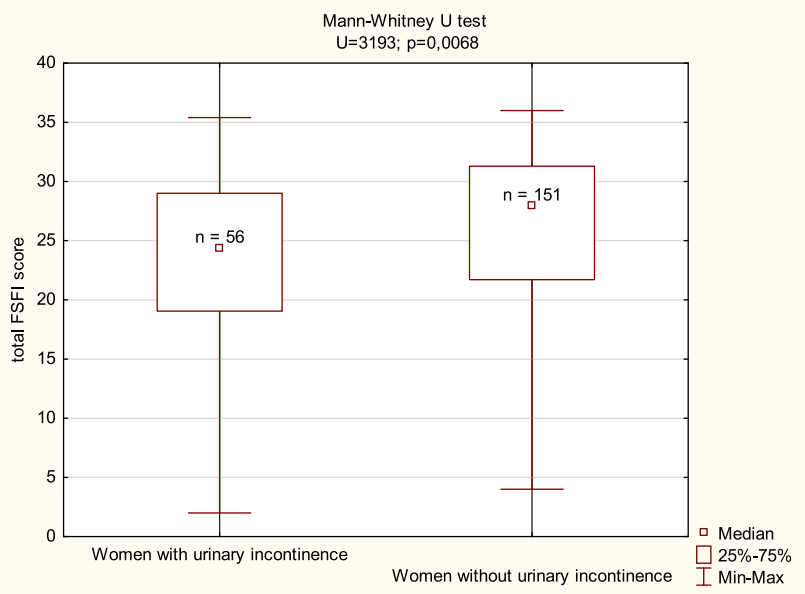

Fig. 3. The relationship between urinary incontinence and FSFI scores $(n=207)$

had a non-significant relationship with desire and orgasm (Table 1).

$61.3 \%$ of the women were breastfeeding exclusively, $23.3 \%$ were mixed feeding, and $15.4 \%$ were exclusively

Table 1. FSFI scores and their relationship with urinary incontinence $(n=207)$

\begin{tabular}{lccccc}
\hline & $\begin{array}{c}\text { Women with } \\
\text { urinary } \\
\text { incontinence } \\
(n=151)\end{array}$ & \multicolumn{2}{c}{$\begin{array}{c}\text { Women } \\
\text { without urinary } \\
\text { incontinence } \\
(n=56)\end{array}$} & \\
\cline { 2 - 4 } & Mean & SD & Mean & SD & $P^{\text {a }}$ \\
\hline Desire & 3.68 & 1.25 & 3.38 & 1.28 & 0.135 \\
Arousal & 4.25 & 1.31 & 3.81 & 1.46 & 0.033 \\
Lubrication & 4.69 & 1.49 & 4.24 & 1.52 & 0.022 \\
Orgasm & 4.39 & 1.58 & 3.99 & 1.65 & 0.063 \\
Satisfaction & 4.50 & 1.35 & 3.97 & 1.32 & 0.006 \\
Pain & 4.38 & 1.65 & 3.84 & 1.70 & 0.032 \\
FSFI & 25.89 & 6.88 & 23.22 & 7.03 & 0.006 \\
\hline
\end{tabular}

${ }^{\mathrm{a}}$ Data were compared using Mann-Whitney U test 


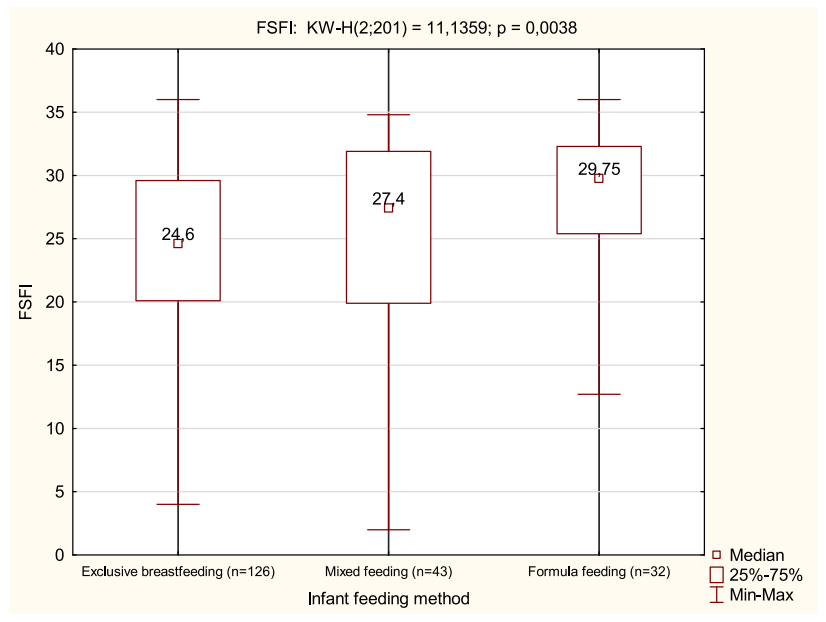

Fig. 4. FSFI scores according to infant feeding method $(n=201)$

formula feeding. Of the breastfeeding women, $65.3 \%$ reported that they breastfed on demand. $27.7 \%$ had painful or bleeding nipples, or both, within the last 4 weeks.

Based on the Kruskal-Wallis test, a significant relationship was found between infant feeding method and total FSFI score $(P=0.003)$. Sexual dysfunction was more common in exclusively breastfeeding mothers than in formula-feeding mothers. Significantly lower FSFI scores were found in the exclusive-breastfeeding group compared to the formula-feeding group $(P=0.004)$. No significant difference was found between the exclusive-breastfeeding group and the mixed-feeding group or between the mixed-feeding and the formula-feeding group (Fig. 4).

\section{DISCUSSION}

Postpartum hormonal changes, health recovery, and potentially painful and prolonged improvement of complications after delivery can influence the physical and emotional health status of women in the postpartum period.

Sexual dysfunction is a highly prevalent health condition that leads to a decrease in quality of life and self-confidence, and an increased in feelings of loneliness. It also affects interpersonal relationships. FSD are considered a public health problem affecting more than $40 \%$ of the world female population [26]. Based on the medical literature, the overall prevalence of postpartum sexual problems has been estimated at 22-86\% [24, 27-28].

Based on our data, almost every second (48.8\%) woman suffered from sexual dysfunction three months after her delivery. The majority of women did not turn back to their sex life within 6 weeks after delivery, which shows the effectiveness of postnatal counselling. The mean time of sexual resumption was two months postpartum, which indicates the need for early counselling by health care professionals about the potential problems of resuming sexual activity.

Breastfeeding is considered one of the most important factors affecting sexual function.
Several studies have shown that mothers who exclusively breastfeed their babies are more likely to suffer from sexual problems, especially painful intercourse [8,29-33]. A few studies with the opposite results can also be found in the literature [12, 13]. In our study, sexual dysfunction was more common in mothers of exclusively breastfed infants than of mixed or formula-fed infants. Exclusive-breastfeeding mothers had significantly lower FSFI scores compared to formulafeeding mothers. We did not find a significant difference between the exclusive-breastfeeding group and the formulafeeding group, as well as between mixed-feeding mothers and formula-feeding mothers. One explanation could be the potentially higher level of fatigue caused by exclusive breastfeeding on demand and night-time nursing. Exclusive breastfeeding means that mothers breastfeed day and night, which suggests higher distress compared to formula-feeding mothers. Breastfeeding mothers could suffer from sleep deprivation due to the frequency of nursing at night, which could be accompanied by sexual dysfunction $[8,34]$.

In the literature, the prevalence of urinary incontinence during pregnancy was found to be between 26 and $58 \%$ [ 35 , 36]. Within 6 months after delivery, it was found to be between 30 and $40 \%$ [19]. In our study, almost 30\% of women reported urine leakage problems at 3 months postpartum. In previous studies, a significant relationship was found between urinary incontinence and both recurrent urinary tract infections and postpartum sexual dysfunction [21, 37, 38]. Dean et al. examined the long-term effect of urinary incontinence on sex life and found it still a risk factor at six years after delivery [39]. In our study, the prevalence of sexual dysfunction was significantly higher in women with urinary incontinence, showing a significantly lower level of total FSFI score.

The effect of urinary incontinence in FSFI domains such as arousal, desire, lubrication, orgasm, satisfaction, and pain is still unclear, according to the international literature. In Akkoca's study, problems with lubrication, satisfaction, and desire were in connection with urinary incontinence, but no relationship was found between dyspareunia and incontinence [40]. Salonia et al. found that urinary incontinence has a negative effect on arousal and elevates the risk of painful intercourse [22]. In another study, urinary incontinence was associated with libido problems, vaginal dryness, and painful intercourse [41]. Similar to previous studies, we also found that women with urinary incontinence had a lower level of arousal, lubrication, and satisfaction than women without urine leakage. They were also more likely to experience dyspareunia. Due to an increased risk of urinary tract infections, women who suffer from urine leakage have a higher risk of sexual dysfunctions [38]. Brown et al. found, that $70 \%$ of women reporting urinary incontinence had not discussed their symptoms with a health care professional [42], which suggests that women with urinary incontinence are more likely to feel embarrassed and ashamed, especially in the postpartum period when body changes occur.

Systems of maternal health care need to include routine inquiry about incontinence and sexual problems in the postpartum period. 


\section{CONCLUSIONS}

We designed a cross-sectional study to assess female sexual dysfunction after delivery and potential risk factors such as urinary incontinence and breastfeeding. Regarding postpartum female sexual dysfunctions, the first 3 months after delivery is a critical period. Almost $50 \%$ of women suffered from sexual dysfunctions 3 months after delivery.

Urinary incontinence and breastfeeding seem to be risk factors for sexual dysfunction. In our study, urinary incontinence had a negative effect on sexual interest, vaginal wetness, and satisfaction; additionally, a relationship was found between urine leakage and dyspareunia. Urinary incontinence may increase the feeling of shame, which can reduce women's self-confidence and can block normal sexual responses.

The Infant feeding method was also significantly associated with sexual disturbances. Exclusive-breastfeeding mothers reported the lowest level of sexual satisfaction compared to mixed-feeding or formula-feeding mothers.

Adequate and early sexual health promotion is required for women during prenatal care and in the postpartum period. These results indicate the need for further investigation to address risk factors and evaluate their relationship with postpartum sexual problems.

Ethical approval: The research was permitted by Semmelweis University Regional Research Ethics Committee (SE REB number: 24/2017).

Author's contribution: KSz designed and performed the experiments, derived the model, and analysed the data in consultation with LSz. KSz presented the results at the Hungarian Medical Association of America - Summer Congress in 2019, Balatonfüred. KSz and LSz wrote the manuscript together.

Conflicts of interest/Funding: The authors declare no conflict of interest. The authors received no financial support for the research, authorship, and/or publication of this article.

\section{REFERENCES}

1. Yildiz $\mathrm{H}$. The relation between prepregnancy sexuality and sexual function during pregnancy and the postpartum period: a prospective study. J Sex Marital Ther 2015;41(1):49-59. https://doi.org/ 10.1080/0092623x.2013.811452.

2. Signorello LB, Harlow BL, Chekos AK, Repke JT. Postpartum sexual functioning and its relationship to perineal trauma: a retrospective cohort study of primiparous women. Am J Obstet Gynecol 2001; 184(5):881-8. https://doi.org/10.1067/mob.2001.113855.

3. Barrett G, Pendry E, Peacock J, Victor C, Thakar R, Manyonda I. Women's sexual health after childbirth. Br J Obstet Gynaecol 2000; 107(2):186-95. https://doi.org/10.1111/j.1471-0528.2000.tb11689.x.

4. Ishak WW, Tobua G. DSM-5 changes in diagnostic criteria of sexual dysfunctions. Reprod Sys Sexual Disorders 2013;2:2. https:// doi.org/10.4172/2161-038X.1000122.
5. Acele EÖ, Karaçam Z. Sexual problems in women during the first postpartum year and related conditions. J Clin Nurs 2012;21(7-8): 929-37. https://doi.org/10.1111/j.1365-2702.2011.03882.x.

6. Barrett G, Pendry E, Peacock J, Victor C, Thakar R, Manyonda I. Women's sexuality after childbirth: A pilot study. Arch Sex Behav 1999;28(2):179-91. https://doi.org/10.1023/a:1018771906780.

7. Klein K, Worda C, Leipold H, Gruber C, Husslein P, Wenzl R. Does the Mode of Delivery Influence Sexual Function after Childbirth? J Womens Health (Larchmt) 2009;18(8):1227-31. https://doi.org/10. 1089/jwh.2008.1198.

8. Lagaert L, Weyers S, Van Kerrebroeck H, Elaut E. Postpartum dyspareunia and sexual functioning: a prospective cohort study. Eur J Contracept Reprod HealthCare 2017;22(3):200-6. https://doi. org/10.1080/13625187.2017.1315938.

9. Nikpour S, Hajikazemi E, Javahari E, Yadavarnikravesh M, Nooritajer M, Jamshidee R. Women's sexuality after childbirth: A cross sectional study. Eur J Sci Res 2006;14(2):268-75.

10. Breastfeeding, World Health Organization [Internet] Geneva: Switzerland; [cited 2019 Nov 15]. Available from: https://www.who. int/topics/breastfeeding/en/.

11. Chayachinda C, Titapant V, Ungkanungdecha A. Dyspareunia and sexual dysfunction after vaginal delivery in Thai primiparous women with episiotomy. J Sex Med 2015;12(5):1275-82. https://doi. org/10.1111/jsm.12860.

12. Anbaran ZK, Baghdari N, Pourshirazi M, Karimi FZ, Rezvanifard M, Mazlom SR. Postpartum sexual function in women and infant feeding methods. J Pak Med Assoc 2015;65(3):248-52.

13. Escasa-Dorne MJ. Sexual functioning and commitment to their current relationship among breastfeeding and regularly cycling women in Manila, Philippines. Human Nat 2015;26(1):89-101. https://doi.org/10.1007/s12110-015-9223-x.

14. Rezaei N, Azadi A, Sayehmiri K, Valizadeh R. Postpartum sexual functioning and its predicting factors among Iranian women. Malays $\mathrm{J}$ Med Sci 2017;24(1):94-103. https://doi.org/10.21315/mjms2017.24.1.10.

15. Yee LM, Kaimal AJ, Nakagawa S, Houston K, Kuppermann M. Predictors of postpartum sexual activity and function in a diverse population of women. J Midwifery Womens Health 2013;58(6): 654-61. https://doi.org/10.1111/jmwh.12068.

16. Connolly A, Thorp J, Pahel L. Effects of pregnancy and childbirth on postpartum sexual function: a longitudinal prospective study. Int Urogynecol J Pelvic Floor Dysfunct 2005;16(4):263-7. https:// doi.org/10.1007/s00192-005-1293-6.

17. Barrett G, Peacock J, Victor CR, Manyonda I. Cesarean section and postnatal sexual health. Birth 2005;32(4):306-11.

18. Abrams P, Cardozo L, Fall M, Griffiths D, Rosier P, Ulmsten U, The standardization of terminology of lower urinary tract function: report from the standardization sub-committee of the International Continence Society. Neurourol Urodyn 2002;21(2):167-78.

19. Su CC, Sun BYC, Jiann BP. Association of urinary incontinence and sexual function in women. Int J Urol 2015;22(1):109-13. https:// doi.org/10.1111/iju.12610.

20. Brown S, Gartland D, Perlen S, McDonald E, MacArthur C. Consultation about urinary and faecal incontinence in the year after childbirth: a cohort study. BJOG 2015;122(7):954-62. https://doi. org/10.1111/1471-0528.12963.

21. Ozkan S, Ogce F, Cakir D. Quality of life and sexual function of women with urinary incontinence. Jpn J Nurs Sci 2011;8(1):11-9. https://doi.org/10.1111/j.1742-7924.2010.00155.x. 
22. Salonia A, Zanni G, Nappi RE, Briganti A, Dehò F, Fabbri F, Sexual dysfunction is common in women with lower urinary tract symptoms and urinary incontinence: results of a cross-sectional study. Eur Urol 2004;45(5):642-8. https://doi.org/10.1016/j.eururo.2003. 11.023 .

23. Baytur YB, Deveci A, Uyar Y, Ozcakir HT, Kizilkaya S, Caglar H. Mode of delivery and pelvic floor muscle strength and sexual function after childbirth. Int J Gynaecol Obstet 2005;88(3):276-80. https://doi.org/10.1016/j.j.ijgo.2004.12.019.

24. Rosen RC, Brown C, Heiman J, Leiblum S, Meston C, Shabsigh R, The Female Sexual Function Index (FSFI): a multidimensional selfreport instrument for the assessment of female sexual function. J Sex Marital 2000;26(2):191-208.

25. Wiegel M, Meston C, Rosen R. The Female Sexual Function Index (FSFI): cross-validation and development of clinical cutoff scores. J Sex Marital Ther 2005;31(1):1-20.

26. McCabe MP, Sharlip ID, Lewis R, Atalla E, Balon R, Fisher AD, Incidence and prevalence of sexual dysfunction in women and men: a consensus statement from the fourth international consultation on sexual medicine 2015. J Sex Med 2016;13(2):144-52. https://doi. org/10.1016/j.jsxm.2015.12.034.

27. Alesheikh A, Jaafarnejad F, Esmaily H, Asgharipour N. The relationship between mode of delivery and sexual function in nulliparous women. JMRH 2016;4(3):635-43.

28. Barbara G, Pifarotti P, Facchin F, Cortinovis I, Dridi D, Ronchetti C, Impact of mode of delivery on female postpartum sexual functioning: spontaneous vaginal delivery and operative vaginal delivery vs Cesarean section. J Sex Med 2016;13(3):393-401. https:// doi.org/10.1016/j.jsxm.2016.01.004.

29. Leeman LM, Rogers RG. Sex after childbirth postpartum sexual function. Obstet Gynecol 2012;119(3):647-55. https://doi.org/10. 1097/AOG.0b013e3182479611.

30. Khajehei M, Doherty M, Tilley PJ, Sauer K. Prevalence and risk factors of sexual dysfunction in postpartum Australian women. J Sex Med 2015;12(6):1415-26. https://doi.org/10.1111/jsm.12901.

31. Khosravi Anbaran Z, Baghdari N, Pourshirazi M, Karimi A. The relationship between women's postpartum sexual function and infant feeding. IJN 2014;5:2-3. https://doi.org/10.22038/IJN.2014.3113.
32. Abdool Z, Thakar R, Sultan AH. Postpartum female sexual function. Eur J Obstet Gynecol Reprod Biol 2009;145(2):133-7. https:// doi.org/10.1016/j.ejogrb.2009.04.014.

33. LaMarre AK, Paterson LQ, Gorzalka BB. Breastfeeding and postpartum maternal sexual functioning: a review. Can J Hum Sex 2003; 12(3-4):151-68.

34. Zamani M, Latifnejad Roudsari R, Moradi M, Esmaeeli H. The relationship between frequency of breastfeeding and sexual distress in postpartum women. JMRH 2018;6(4):1447-53. https://doi.org/ 10.22038/jmrh.2018.26061.1285.

35. Eason E, Labrecque M, Marcoux S, Mondor M. Effects of carrying a pregnancy and of method of delivery on urinary incontinence: a prospective cohort study. BMC Pregnancy Childbirth 2004;4(1):4.

36. Wesnes SL, Rotveit G, Bø K, Hunskaar S. Urinary incontinence during pregnancy. Obstet Gynecol 2007;109(4):922-8.

37. Su CC, Sun BYC, Jiann BP. Association of urinary incontinence and sexual function in women. Int J Urol 2015;22(1):109-13. https:// doi.org/10.1111/iju.12610.

38. Yeniel AO, Petri E. Pregnancy, childbirth, and sexual function: perceptions and facts. Int Urogynecol J 2014;25(1):5-14. https://doi. org/10.1007/s00192-013-2118-7.

39. Dean N, Wilson D, Herbison P, Glazener C, Aung T, Macarthur C. Sexual function, delivery mode history, pelvic floor muscle exercises and incontinence: a cross-sectional study six years post-partum. Aust N Z J Obstet Gynaecol 2008:48(3):302-11. https://doi.org/10. 1111/j.1479-828X.2008.00854.x.

40. Akkoca AN, Kurt R, Ozdemir ZT, Yengil E, Özer C, Arica S, The prevalence of urinary incontinence, sexual dysfunction and quality of life in women of reproductive age admitted to urogynecology departments. Acta Med Mediterr 2014;3(5):1059-66.

41. Handa VL, Harvey L, Cundiff GW, Siddique SA, Kjerulff $\mathrm{KH}$. Sexual function among women with urinary incontinence and pelvic organ prolapse. Am J Obstet Gynecol 2004;191(3):751-6.

42. Brown S, Gartland D, Perlen S, McDonald E, MacArthur C. Consultation about urinary and faecal incontinence in the year after childbirth: a cohort study. BJOG 2015;122(7):954-62. https://doi. org/10.1111/1471-0528.12963. 